\title{
THE
}

\section{Temporal Associations between Psychological and Physical Intimate Partner Violence: A Cross-Lag Analysis}

Hans Saint-Eloi Cadely

University of Rhode Island, hsainteloicadel@uri.edu

Joe F. Pitman

Gregory S. Pettit

Jennifer E. Lansford

John E. Bates

Follow this and additional works at: https://digitalcommons.uri.edu/hdf_facpubs

The University of Rhode Island Faculty have made this article openly available.

Please let us know how Open Access to this research benefits you.

This is a pre-publication author manuscript of the final, published article.

Terms of Use

This article is made available under the terms and conditions applicable towards Open Access

Policy Articles, as set forth in our Terms of Use.

\section{Citation/Publisher Attribution}

Saint-Eloi Cadely, H., Pittman, J. F. Pettit, G. S., Lansford, J. E., Bates, J. E., Dodge, K. A., \& HoltzworthMunroe, A. (In Press). Temporal associations between psychological and physical intimate partner violence: A cross-lag analysis. Partner Abuse, 11(1), 22-38. doi: 10.1891/1946-6560.11.1.22

Available at: http://dx.doi.org/10.1891/1946-6560.11.1.22

This Article is brought to you for free and open access by the Human Development and Family Science at DigitalCommons@URI. It has been accepted for inclusion in Human Development and Family Science Faculty Publications by an authorized administrator of DigitalCommons@URI. For more information, please contact digitalcommons-group@uri.edu. 


\section{Authors}

Hans Saint-Eloi Cadely, Joe F. Pitman, Gregory S. Pettit, Jennifer E. Lansford, John E. Bates, Kenneth A. Dodge, and Amy Holtzworth-Munroe 
Temporal Associations between Psychological and Physical Intimate Partner Violence: A Cross-Lag Analysis

Hans Saint-Eloi Cadely, Joe F. Pittman, Gregory S. Pettit, Jennifer E. Lansford, John E. Bates, Kenneth A. Dodge, and Amy Holtzworth-Munroe University of Rhode Island

Auburn University

Duke University

Indiana University

Author Note

Hans Saint-Eloi Cadely, Department of Human Development and Family Studies, University of Rhode Island; Joe F. Pittman, Department of Human Development and Family Studies, Auburn University; Gregory S. Pettit, Department of Human Development and Family Studies, Auburn University; Jennifer E. Lansford, Center for Child and Family Policy, Duke University; John E. Bates, Department of Psychological and Brain Sciences, Indiana University; Kenneth A. Dodge, Center for Child and Family Policy, Duke University; Amy Holtzworth-Munroe, Department of Psychological and Brain Sciences, Indiana University.

The Child Development Project has been funded by grants MH42498, MH56961, MH57024, and MH57095 from the National Institute of Mental Health, HD30572 from the Eunice Kennedy Shriver National Institute of Child Health and Human Development, and DA016903 from the National Institute on Drug Abuse.

Correspondence concerning this article should be addressed to Hans Saint-Eloi Cadely, Department of Human Development and Family Studies, University of Rhode Island, Kingston, RI 02881. hsainteloicadel@uri.edu. 


\begin{abstract}
The present study examined the relationship between psychological and physical forms of intimate partner violence (IPV) across four waves of data during the developmental period of young adulthood. The links from early psychological aggression to later physical aggression and from early physical aggression to later psychological aggression across waves were tested while controlling for their cross-time stabilities and concurrent associations. IPV data were collected annually from 434 young adult respondents involved in a romantic relationship at least once during the respective years from the ages of 22-25. On average, participants provided IPV data for three out of the four years covered by the study $(M=2.82 ; S D=1.14)$. Results of a crosslagged SEM model indicated significant cross-time stabilities as well as significant, positive concurrent associations for both forms of aggression. Most important to this study were the findings that, controlling for these stabilities and concurrent associations, early psychological aggression was a consistent positive predictor of later physical aggression across waves whereas the opposite direction from early physical aggression to later psychological aggression was either non-significant or significant and negative.
\end{abstract}

Keywords: cross-lag analysis, intimate partner violence, physical aggression, psychological aggression, young adulthood 
Temporal Associations between Psychological and Physical Intimate Partner Violence:

\section{A Cross-Lag Analysis}

Intimate partner violence (IPV) consists of aggressive behaviors expressed towards one's romantic partner. These behaviors can be expressed through psychological, physical, and sexual aggression; however, because sexual aggression was not assessed in the present study, it will be excluded from this discussion. Psychological aggression consists of verbal and non-verbal behaviors including insulting, criticizing, or intimidating one's partner (Straus, Hamby, BoneyMcCoy, \& Sugarman, 1996). Physical aggression is comprised of physically harmful behaviors directed towards one's romantic partner, such as grabbing, pushing, slapping, hitting, and other more hurtful actions (Straus et al., 1996; Foshee et al., 2009).

For nearly three decades, an underlying assumption addressing the emergence of aggression in relationships has proposed that less severe and more normative forms of aggression may escalate over time (i.e., psychological aggression may precede and escalate to physical aggression). This underlying assumption has served as a conceptual framework and guided considerable illuminating research. For instance, O’Leary and colleagues conducted an important series of longitudinal studies with samples of adolescents and young adults suggesting that psychological aggression may lead to physical aggression (Murphy \& O’Leary, 1989; O’Leary, Malone, \& Tyree, 1994; O’Leary \& Slep, 2003). In an adolescent sample, O’Leary and Slep (2003) showed that the perpetration of psychological aggression at one point was related to the perpetration of physical aggression three months later. Murphy and O’Leary (1989) found, among a sample of young adult couples, that the perpetration of psychological aggression assessed prior to marriage and six months after marriage was related to the perpetration of physical aggression 18 to 30 months after marriage. From this same sample, O'Leary et al. 
(1994) found that participants who engaged in psychological aggression at 18 months of marriage were more likely to engage in physical aggression at 30 months of marriage. Together, these findings could be taken as support for the view that psychological aggression escalates to physical aggression over time. However, such a conclusion goes somewhat beyond the data because the temporal ordering was presented in one direction only (psychological to physical) and the analyses failed to control for prior and current levels of each form of aggression.

The purpose of this study was to examine the temporal organization of these associations. Specifically, the relationships between early psychological and later physical aggression and between early physical and later psychological aggression were modeled concomitantly. The studies by O'Leary and colleagues (Murphy \& O'Leary, 1989; O’Leary et al., 1994; O’Leary \& Slep, 2003) clearly support a conceptual organization that places psychological aggression ahead of physical aggression in time, but there are at least two other possibilities. One of these is that aggressiveness of both forms co-emerge. The other is that, at least in some instances, physical aggression could be temporally prior. To adequately address the question of these temporal associations, they must be examined simultaneously in one model with longitudinal observations of both types of aggression (Rogosa, 1980).

Evidence suggestive of a co-emergence of physical and psychological aggression can be found in cross-sectional research studies, which have documented that physical aggression rarely occurs in the absence of psychological aggression (see Carney \& Barner, 2012 for a review of the literature; Burman, John, \& Margolin, 1992; Cordova, Jacobson, Gottman, Rushe, \& Cox, 1993; Lloyd, 1996; Margolin, John, \& Gleberman, 1988; Sabourin, Infante, \& Rudd, 1993). In their review of the literature, Carney and Barner (2012) found that individuals were up to four times more likely to experience psychological aggression if they were also experiencing physical 
abuse in their relationship. Furthermore, Follingstad, Rutledge, Berg, Hause, and Polek (1990) found that over $98 \%$ of their sample of physically abused women also reported psychological abuse by their romantic partner. This pattern suggests that each type of aggression supports the occurrence of the other. In samples of adolescents, Cano, Avery-Leaf, Cascardi, and O'Leary (1998) and O’Leary and Slep (2003) found that perpetrating psychological aggression was related to perpetrating physical aggression. Bookwala, Frieze, Smith, and Ryan (1992) found that college students using psychological aggression reported perpetrating physical aggression. Furthermore, Hamby and Sugarman (1999) found for college students that perpetrating more severe forms of psychological aggression was related to the perpetration of more severe forms of physical aggression. More recent studies among adolescents and young adults revealed similar patterns. Bates, Graham-Kevan, and Archer (2014) found that both men and women in their largely young adult sample who perpetrated controlling forms of psychological IPV were also likely to perpetrate verbal and physical IPV. Additionally, Fawson (2015) found an association between the use of controlling forms of psychological IPV and the perpetration of psychological, physical, and sexual IPV among adolescents. The strong concurrence of these forms of aggression is clearly evident in the literature, but the temporal organization of these forms of aggression remains an important question to ask directly. If one form precedes the other, there is the possibility that it contributes to the emergence of the other. Therefore, in the examination of longitudinal temporal associations, concurrent associations must be controlled (Rogosa, 1980).

Like their concurrent associations, the cross-time stabilities of physical and psychological aggression are also well documented. Longitudinal studies reveal considerable stability in the perpetration of physical aggression over time among samples of high school students (Fritz \& Slep, 2009; O’Leary \& Slep, 2003) as well as young adult couples (Capaldi et al., 2003) and 
particularly among married/cohabiting adult males (Aldarondo, 1996; Lorber \& O’Leary, 2004; Woffordt, Mihalic, \& Menard, 2004). Timeframes for stability assessments in these studies range from three months (O’Leary \& Slep, 2003) to three years (Woffordt et al., 2004) and are based on physical aggression data collected at two-to-four time points (Aldarondo, 1996; Capaldi et al., 2003; Fritz \& Slep, 2009; Lorber \& O’Leary, 2004). Similar results are found for psychological aggression. Fritz and O’Leary (2004) found a stable pattern of perpetrating psychological aggression among young adult women across a 10-year interval, and Fritz and Slep (2009) found it among a sample of male and female adolescents across a one-year interval. Taken together, these two sets of findings suggest that both psychological and physical aggression tend to remain stable over time. Important to a strong test of temporal organization is accounting for these stabilities and their concurrent associations when assessing the cross-lag longitudinal associations between them (Rogosa, 1980). By implementing these controls, we ensured that the longitudinal, cross-lag associations observed model the unique variance accounted for by earlier forms of each type of aggression in subsequent reports of the other and hence increase confidence in the temporal contributions of each type of aggression to the other over time.

Our central research question sought to establish whether either form of aggression makes a reliable, unique contribution to the subsequent expression of the other or whether both forms of aggression simply vary together over time. Although the temporal relationships between psychological and physical aggression have yet to be estimated simultaneously, there is enough conceptual rationale and sufficient evidence to allow us to expect that psychological aggression will precede physical aggression (e.g., Murphy \& O’Leary, 1989; O'Leary et al., 1994; O’Leary \& Slep, 2003). Additionally, given the consistency in the literature of longitudinal 


\section{stability in psychological and physical aggression as well as their concurrent associations, we}

expected both sets of these associations to be significant and positive.

Importantly, we examined these associations during a four-year span of early adulthood. This developmental period is important because this is when more intimate and longer-term relationships are likely to be formed (Arnett, 2004; Carver, Joyner, \& Udry, 2003; Montgomery, 2005) and reports of IPV are likely to persist during this developmental period (Author citation; Cui, Ueno, Gordon, \& Fincham, 2013; Gomez, 2011). The following demographic factors were controlled because of their documented significance on reports of IPV: sex (Archer, 2000), race (Caetano, Field, Ramisetty-Mikler, \& McGrath, 2005; Holt \& Espelage, 2005) and socioeconomic status (SES) (Aldarondo \& Sugarman, 1996; O’Keefe, 1998).

\section{Method}

\section{Participants}

Participants were part of the Child Development Project (CDP), a longitudinal study that examined children's social development and adjustment up to adulthood (Pettit, Lansford, Malone, Dodge, \& Bates, 2010). The original sample $(N=585)$ was selected from registering students (and their parents) in the kindergarten of selected public schools that represented the demographic diversity within the following three cities: Knoxville, Tennessee, Nashville, Tennessee, and Bloomington, Indiana in 1987 when data collection began. Over $90 \%$ of the original sample has been retained in this long-term study (although not necessarily at every wave). To be included in the current analysis, participants had to have been romantically involved in a given year and had to provide IPV data for that relationship during the data collection for that year. A total of 434 participants (74\% of the original sample) met these criteria 
for at least one wave during the ages of 22-25. On average, these participants provided IPV data for approximately three out of four waves $(M=2.82 ; S D=1.14)$.

Across waves, between $23 \%-32 \%$ of participants were dating $(32.3 \%$ at age $22,28.8 \%$ at age $23,26.5 \%$ at age 24 , and $22.6 \%$ at age 25$)$, between $18 \%-23 \%$ were cohabiting (18.9\% at age $22,22.6 \%$ at age $23,21.7 \%$ at age 24 , and $18.2 \%$ at age 25 ), and between $14 \%-30 \%$ were married $(14.3 \%$ at age $22,21.4 \%$ at age $23,25.3 \%$ at age 24 , and $29.5 \%$ at age 25$)$. Taken together, therefore, between $65 \%-74 \%$ of the eligible subsample were represented in each wave. Although most participants $(64.3 \%)$ reported on the same romantic partner each time they participated, approximately $28.1 \%$ reported on two partners across waves, $6.7 \%$ reported on three, and $0.9 \%$ reported on four ( $n$ of partners over 4 years: range: $1-4 ; M=1.44 ; S D=.66$ ).

Chi-square analyses revealed that males $\left(\chi^{2}(1)=23.31, p<.001\right)$ and minorities were slightly overrepresented in the excluded part of the sample $\left(\chi^{2}(1)=6.08, p<.05\right)$. The analysis sample contained was $53.9 \%$ female and $83.9 \%$ European-Americans. Approximately $14.7 \%$ were African-Americans and $1.4 \%$ were of other racial backgrounds. When the study began, roughly $88.2 \%$ of participants' mothers and $75.6 \%$ of their fathers reported a high school education or higher. According to the Hollingshead scale (1975) collected at the beginning of the study, the majority of the analysis sample belonged to middle-class families, but the full range of the scale was represented (range: $1-5 ; M=3.37 ; S D=1.15$ ). Also, at the beginning of the study, $62.9 \%$ of the parents of the analysis sample were married to each other, $0.7 \%$ were cohabiting, and the remainder were single, divorced, separated, or remarried.

\section{Measures}

IPV. Selected items from the Revised Conflict Tactics Scale (CTS2; Straus et al., 1996) were used at ages 22-25. One additional item was derived from the Psychological Maltreatment 
of Women Inventory (PMWI; Tolman, 1989) as an additional assessment of psychological aggression. Seven items were used to assess psychological aggression perpetration (i.e., insulting, destroying partner's belongings, shouting or yelling, cruel put downs, stomping away from a disagreement, spitefulness, and threatening to hit or throw) and 11 items were used to assess physical aggression perpetration (i.e., throwing something, twisting a partner's arm or hair, pushing or shoving, punching or hitting, slamming against a wall, grabbing, slapping, kicking, choking, beating up, and using a knife or gun).

Items were originally assessed on a 7-point scale that produced severely skewed data that did not improve with data transformations. In order to reduce the skewness of the data, items were recoded to a 4 -point scale $(0=$ Never, $1=$ Once or twice in the past year, $2=$ More than twice a year but less than once a month, and $3=$ Once a month or more). At each wave, a composite mean score was calculated for psychological and physical aggression items. Higher scores indicated more perpetration for each type of aggression. Cronbach alphas averaged .78 across the four waves for psychological aggression (range: $0.74-0.81$ ) and .79 for physical aggression (range: $0.70-0.91$ ).

Control Variables. Both sex and race were dummy coded (Sex: $0=$ Male, $1=$ Female; Race: 0 = European-Americans, $1=$ Minorities (African-Americans \& Others $)$ ). The Hollingshead (1975) four-factor index was used to assess SES. Scores were coded on a 5-point scale where higher scores indicated higher SES $(M=3.37 ; S D=1.15)$ (see Table 1 for means, standard deviations, and intercorrelations of control variables and composite mean scores for psychological and physical aggression).

\section{Plan of Analysis}


Analyses were conducted in MPLUS Version 7 (Muthén \& Muthén, 1998-2012). Crosslag analysis was used to address our research question (see Figure 1). Italicized lowercase letters in the figure represent the following pathways: (a) stability pathways for psychological aggression across waves, $\left(a^{\prime}\right)$ stability pathways for physical aggression across waves, $(b)$ concurrent associations between psychological and physical aggression within each wave, $(c)$ cross-lag pathways of psychological aggression at one wave predicting physical aggression at the next wave, and ( $\left.c^{\prime}\right)$ cross-lag pathways of physical aggression at one wave predicting psychological aggression at the next wave. The demographic controls sex, race, and SES were modeled as predictors of psychological and physical aggression at age 22 .

Model fit was examined by the chi-square statistic $\left(\chi^{2}\right)$, the comparative fit index (CFI), the Tucker-Lewis Index (TLI), the root mean square error of approximation (RMSEA), and the standardized root mean square residual (SRMR). Good model fit is indicated by a non-significant $\chi^{2}$ (Kline, 2016), a CFI and/or TLI between $.90-1.00$ (Bentler \& Bonnett, 1980), an RMSEA of .10 or lower (Harlow, 2014), and a SRMR of .10 or lower (Kline, 2016).

As is common in many longitudinal studies, observations across waves can be missing for various reasons. Most relevant to the current study is that IPV data were missing when participants were not involved in a relationship in a given year or could not be reached at the time of data collection. Both of these reasons for missing data could occur for a wide range of random reasons. Missing data were handled using Full Information Maximum Likelihood (FIML), which is a highly recognized and recommended procedure for the handling of data that are missing at random. Rather than deleting cases with incomplete data (i.e., listwise deletion), or substituting imputed values where data are missing (e.g., mean substitution or regression-based substitutions), FIML uses all the available data for each participant and estimates parameters 
using the available data including the random variables where data are missing. This procedure has been shown to yield superior parameter estimates and statistical properties compared to either listwise deletion or single imputation methods (Schafer \& Graham, 2002).

\section{Results}

A structural equation model (SEM) containing stability, concurrent, and cross-lag associations was fit to the data (see Figure 2). Given the sensitivity of the $\chi^{2}$ statistic to sample size (Kline, 2016), it was not surprising that the test was significant $\left(\chi^{2}=107.33, p<.001 ; \mathrm{DF}=\right.$ 30). However, Wheaton, Muthén, Alwin, and Summers (1979) maintain that a $\chi^{2} / \mathrm{DF}$ ratio below five supports a favorable conclusion about fit in large sample models. In the current case, this criterion is solidly met $(107.33 / 30=3.58)$. Three out of the remaining four fit indices also supported the interpretation that our structural model offered a good fit to the data $(\mathrm{CFI}=.92$; RMSEA $=.08,90 \%$ Confidence Interval $(C I)=[0.06,0.09] ;$ SRMR $=.09)$. Although the TLI of .86 missed the criterion for good fit, it was not a large departure. Taken together, we view the observed fit indices as acceptable for proceeding with the structural model.

Results revealed the expected significant and positive stability associations for psychological and physical aggression across waves. Specifically, early reports of each form of aggression predicted later reports of the same behaviors across waves. It is noteworthy that the stability coefficients across waves were consistently strong for psychological aggression and more than twice as large as for physical aggression, where they were of small to moderate strength (see Figure 2). Concurrent associations were also significant, positive, and in the moderate-to-strong range at each wave signifying that reports of psychological and physical aggression were related at each wave. 
Most central to our interest were the cross-lag coefficients estimated with the stabilities and concurrent associations for psychological and physical aggression statistically controlled. Above and beyond the stability of psychological and physical aggression and the concurrent associations between the two forms of aggression, psychological aggression made a unique, positive and statistically significant contribution to the prediction of subsequent physical aggression for all three waves. The standardized coefficients for these paths ranged from .18 to .30 , indicating that a standard deviation increase in psychological aggression at one wave was associated with an increase in physical aggression at the next wave of about one-fifth to onethird of a standard deviation with all statistical controls in place. These contributions are considered small-to-moderate (Cohen, 1969, 1992; Light, Singer, \& Willett, 1990).

Interestingly, in the same context of statistical control, earlier physical aggression either made no unique contribution to the prediction of subsequent psychological aggression or a negative one. More physical aggression at age 24 predicted less psychological aggression at age 25. The size of the association was small. The standardized coefficient was -.12 , indicating that a standard deviation increase in physical aggression at age 24 was associated with just over onetenth of a standard deviation decrease in psychological aggression at age 25 .

For each wave in which stabilities and cross-lag parameters were estimated, the total- $R^{2} \mathrm{~s}$ for both psychological and physical aggression were significant and substantial. For physical aggression, the $R^{2}$ s ranged from .10 to .21 , indicating that around one-to-two tenths of the variance in physical aggression could be accounted for by knowing the stability of physical aggression across time, its concurrent association with psychological aggression, and the prior year's level of psychological aggression. For psychological aggression, the $R^{2}$ s ranged from .38 to .51 indicating that around a third to a half of its variance at each wave was explained by the 
stability of psychological aggression across waves, the concurrent association with physical aggression, and the unique association of last year's physical aggression. Given that earlier physical aggression was not statistically related to subsequent psychological aggression in two of three waves and only minimally significant in the third, it appears that the substantial $R^{2} \mathrm{~s}$ for psychological aggression across waves are due to its substantial temporal stability and its considerable concurrent association with physical aggression. Overall, our findings suggest a temporal organization in which early psychological aggression is a unique predictor of subsequent physical aggression whereas the reverse is generally not the case (see Figure 2) ${ }^{1}$.

\section{Discussion}

The purpose of the present paper was to examine psychological aggression and physical aggression during young adulthood through a study of their temporal associations. Although previous studies have suggested that physical aggression may be, at least in part, a progression from earlier psychological aggression (Murphy \& O’Leary, 1989; O’Leary et al., 1994; O’Leary \& Slep, 2003), this notion has not received a direct, strong test in the IPV literature. Through the implementation of a cross-lag methodology, the present study provided a stronger test by estimating cross-lag associations while controlling for the concurrent and stability associations for both behaviors across waves (Rogosa, 1980). It is important to note that although the estimates of these significant cross-lag relations are small-to-moderate (Cohen, 1969, 1992; Light et al., 1990), the unique associations estimated in the context of statistical control suggest

\footnotetext{
${ }^{1}$ At the recommendation of reviewers and because of the substantial literature on gender-based associations with rates of IPV (see meta-analyses by Archer, 2000; 2002), multi-group analyses were conducted to examine whether gender moderated the cross-lag associations. Results indicated that the same pattern of findings emerged across both groups. Specifically, early psychological aggression was a consistent predictor of later physical aggression for both males and females whereas physical aggression either did not predict subsequent psychological aggression or it did so negatively.
} 
an important pattern. Because these findings are based on correlational analyses, our findings cannot be interpreted as causal. Nevertheless, our findings portray a consistent, unique positive temporal contribution from earlier psychological to later physical aggression across four annual waves of data collected from young adults. Specifically, more psychological aggression at each wave predicted more physical aggression at the next wave over the four-year period in the early years of adulthood. Overall, these findings enhance our confidence that psychological aggression increases the likelihood of later physical aggression as several researchers proposed (e.g., Murphy \& O’Leary, 1989; O’Leary et al., 1994; O’Leary \& Slep, 2003). Indeed, the consistency of this pattern suggests that psychological aggression may be an escalator to physical aggression, or a type of "gateway" behavior that may not determine later physical aggression but is associated with an increase in its likelihood.

As a more normative behavior, psychological aggression is more widely used as a conflict tactic and may be perceived as a less dangerous tactic for the perpetrator to use (Follingstad \& Rogers, 2013). Therefore, as O'Leary and colleagues argued, couples who are dealing with conflict or dissatisfaction in their relationship may first turn to psychological aggression before progressing to physical aggression (Murphy \& O’Leary, 1989; O’Leary et al., 1994). This seems especially likely among young adults who have less relationship experience and may be experimenting with different ways to address relationship issues (Creasey \& HessonMcInnis, 2001; Creasey, Kershaw, \& Boston, 1999).

Interestingly, although the well documented concurrent association between physical and psychological aggression was observed (Bates et al., 2014; Bookwala et al., 1992; Burman et al., 1992; Carney \& Barner, 2012; Cordova et al., 1993; Fawson, 2015; Lloyd, 1996; Margolin et al., 1988; O’Leary \& Slep, 2003; Sabourin et al., 1993), we found no support for the conclusion that 
earlier physical aggression contributed to the emergence of later psychological aggression. Rather, some evidence suggested that earlier physical aggression may be associated with a decrease in subsequent psychological aggression. If this finding can be replicated, it is interesting and deserves further attention. Research suggests that impulsivity in general as well as antisocial, criminal, and acting out behaviors decrease with age (Elliot \& Menard, 1996; Moffitt, 1993, 2003, 2007; Steinberg et al., 2008), which could account for the small negative longitudinal association. Alternatively, such a pattern also could emerge if negative consequences from earlier physical aggression (e.g., negative judgments from peers or feelings of remorse and guilt) lead to reassessments of use of IPV (e.g., Holtzworth-Munroe, Meehan, Herron, Rehman, \& Stuart, 2003; Holtzworth-Munroe \& Stuart, 1994). Future studies will need to assess postaggressive consequences directly to substantiate this interpretation. Yet another possibility may be that this pathway reflects the transition to a more committed relationship. In the present study's sample, the marriage rates increased, whereas dating and cohabitation rates declined across waves. It may be that, on average, relationships become less aggressive as individuals develop more social skills and form more permanent, committed relationships. For instance, over a 10-year period, Fritz and O'Leary (2004) found that wives' rates of perpetrating IPV towards their spouse decreased. Therefore, future studies will need to examine whether relationship commitment plays a role in the de-escalation of physical aggression during the later years of a relationship.

Our central findings of an apparent temporal pattern between psychological and physical aggression takes nothing away from the well documented stability for both forms of aggression and their moderate-to-strong concurrent relationships. Indeed, these are consistent with the existing literature which has documented stability and concurrent associations during 
adolescence (Cano et al., 1998; Fawson, 2015; Fritz \& Slep, 2009; O’Leary \& Slep, 2003) and adulthood (Aldarondo, 1996; Bates et al., 2014; Bookwala et al., 1992; Capaldi et al., 2003; Carney \& Barner, 2012; Fritz \& O’Leary, 2004; Hamby \& Sugarman, 1999; Lorber \& O’Leary, 2004; Woffordt et al., 1994). Our study shows these associations across multiple time points among young adults, suggesting that these associations continue over time. However, the stability and concurrent associations of psychological and physical aggression need to be considered in the context of their respective rates of occurrence. Whereas 50\%-59\% of our participants acknowledged perpetrating some type of psychological aggression across waves, only between $14 \%-16 \%$ admitted perpetrating some form of physical aggression within the same period. The literature documents that physical aggression without psychological aggression is rare (see Carney \& Barner, 2012 for a review), however, the reverse is not rare. This study demonstrates that within the context of these well documented stabilities and concurrent associations there exists a small unique contribution from early psychological aggression to later physical aggression, but this contribution does not apply to everyone. Most perpetrators of psychological aggression may never perpetrate physical aggression in their close relationships. Our findings suggest, however, that the risk of using physical aggression increases for users of psychological aggression. Given that young adulthood is a critical time period for the formation of romantic relationships (Arnett, 2000, 2004), our findings bring out evidence of a risk factor that is important for individuals within this age group to understand.

\section{Although our findings allow us to argue with more confidence that psychological}

aggression may precede physical aggression, we are not yet ready to argue that this pattern applies for all perpetrators of IPV. Johnson and colleagues (Johnson, 1995, 2005, 2006; Johnson \& Ferraro, 2000) present a typology of relationship aggression that emphasizes the motivation 
behind the aggression expressed. The essential distinction is between a motive to resolve a relationship situation that may be beyond the social skills of participants (situational) versus a motive to control the behavior of a partner (terroristic). Given the nature of our sample, it is safer to argue that our findings may be applicable to the former situational motive, i.e., individuals who perpetrate aggression within their relationship due to skill deficits in anger management, relationship communication, and/or conflict-resolution. Although information regarding the motives behind the aggression was not collected by the CDP, aspects of the aggression reported by respondents allow us to assume that our sample is more representative of a situational type. Specifically, participants within the CDP who perpetrated IPV mainly reported minor forms of such behaviors. Furthermore, gender symmetry was shown in the rates of psychological and physical aggression reported. According to Johnson (1995, 2005, 2006; Johnson \& Ferraro, 2000), these aspects are more characteristic of the situational type of aggression. Future studies will need to examine our research questions among participants and couples who express controlling motivations for their aggression to establish the temporal organization of their psychological and physical aggression.

\section{Future Directions \& Limitations}

Three aspects of the current study are important to the interpretation of our findings and may offer some future directions for researchers focused on IPV. First, this study only analyzed IPV data from the young adults being followed by this prospective, longitudinal study and not their relationship partners. Second, these research participants were $22-25$ years old during the data collection period, and relationships in this developmental period were temporary for a substantial fraction of the sample. Consequently, our analysis frames IPV as an attribute of individuals reporting on their own behavior while in relationships rather than as a two-person 
dynamic reflective of the experiences of partners in their relationships. Much longitudinal research on IPV has been conducted with married couples (O’Leary et al., 1989; 1994) or adolescents who were with the same dating partner over time (O’Leary \& Slep, 2003). In both of these research scenarios the continuity of the couple relationship allows for an individual's report to reflect an attribute of the couple. In the present study's sample, approximately $36 \%$ of participants changed romantic partners at least once between the ages of 22-25. Hence, using an individual's report across multiple waves and, in a substantial minority of instances, across multiple partners, it seems necessary to interpret our findings in the context of an individual's experience rather than a relationship dynamic. Future research with reports of aggression from both partners that attends to the continuity and/or discontinuity of partnerships over time would be valuable. Furthermore, the influence of relationship commitment on the negative association between early physical and later psychological aggression is worthy of investigation. Should this unexpected pattern be replicated in future studies, it could change the way we think about the emergence of psychological and physical aggression.

A few minor limitations to this study are worth noting. For example, this community sample was limited in its diversity, with a majority of white and middle-class members. Furthermore, females were slightly over-represented in the analysis sample. However, the sample was not homogeneous. Sixteen percent of the sample identified with minority ethnicities and the full range of the socioeconomic spectrum, as measured by the Hollingshead scale (1975), were included. Nevertheless, future directions for this work should include replicating the main study's findings in more diverse and more at-risk (e.g., low SES youths, inner-city youths, or juvenile delinquents) samples to add to the generalizability of these findings. 
Although the instrument used to assess IPV included minor and severe forms of such behaviors, mainly minor forms of IPV were reported by the community sample of this study. Furthermore, no data were available about the motivations of the IPV perpetrators. Thus, future studies will need to examine whether and how well these findings can be generalized to populations for whom more severe IPV perpetration may be prevalent and/or for whom controlling motivations are active in the use of IPV.

In summary, our findings contribute to the literature by increasing our confidence in a temporal organization whereby early psychological aggression reveals a statistically significant and meaningful unique association with the expression of later physical aggression while the stabilities and concurrent associations between these behaviors are controlled. The opposite pattern from early physical to later psychological aggression either was not supported or was negative in direction. Future studies will need to examine these relationships in earlier and later developmental periods and in other cultures and subcultures that vary in their use of these behaviors to determine whether our findings reflect an early adulthood relationship phenomenon or generalize more widely across the lifespan. 


\section{References}

Aldarondo, E. (1996). Cessation and persistence of wife assault: A longitudinal analysis. American Journal of Orthopsychiatry, 66(1), 141-151. DOI: 10.1037/h0080164

Aldarondo, E., \& Sugarman, D. B. (1996). Risk marker analysis of the cessation and persistence of wife assault. Journal of Consulting and Clinical Psychology, 64(5), 1010-1019. DOI: $\underline{10.1037 / 0022-006 X .64 .5 .1010}$

Archer, J. (2000). Sex differences in aggression between heterosexual partners: A meta-analytic

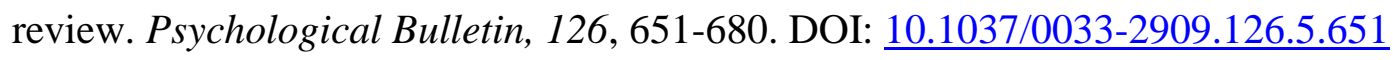

Archer, J. (2002). Sex differences in physically aggressive acts between heterosexual partners: A meta-analytic review. Aggression and Violent Behavior, 7, 313-351. DOI: 10.1016/S1359-1789(01)00061-1

Arnett, J. J. (2000). Emerging adulthood: A theory of development from the late teens through the twenties. American Psychologist, 55(5), 469-480. DOI: 10.1037//0003066X.55.5.469.

Arnett, J. J. (2004). Emerging adulthood: The winding road from the late teens through the twenties. New York, NY: Oxford University Press.

Bates, E. A., Graham-Kevan, N., \& Archer, J. (2014). Testing predictions from the male control theory of men's partner violence. Aggressive Behavior, 40, 42-55.

Bentler, P. M., \& Bonnett, D. G. (1980). Significance tests and goodness of fit in the analysis of covariance structures. Psychological Bulletin, 88, 588-606. DOI: 10.1037/00332909.88.3.588

Bookwala, J., Frieze, I. H., Smith, C., \& Ryan, K. (1992). Predictors of dating violence: A multivariate analysis. Violence and Victims, 7, 297-308. 
Burman, B., John, R. S., \& Margolin, G. (1992). Observed patterns of conflict in violent, nonviolent, and nondistressed couples. Behavioral Assessment, 14, 15-37.

Caetano, R., Field, C. A., Ramisetty-Mikler, S., McGrath, C. (2005). The 5-year course of intimate partner violence among white, black, and hispanic couples in United States. Journal of Interpersonal Violence, 20(9), 1039-1057. DOI: 10.1177/0886260505277783

Cano, A., Avery-Leaf, S., Cascardi, M., \& O’Leary, D. (1998). Dating violence in two high school samples: Discriminating variables. The Journal of Primary Prevention, 18(4), 431-446. DOI: 10.1023/A: 1022653609263

Capaldi, D. M., Shortt, J. W., \& Crosby, L. (2003). Physical and psychological aggression in atrisk young couples: Stability and change in young adulthood. Merrill-Palmer Quaterly, 49(1), 1-27. DOI: 10.1353/mpq.2003.0001

Carney, M. M., \& Barner, J. R. (2012). Prevalence of partner abuse: Rates of emotional abuse and control. Partner Abuse, 3(3), 286-335. DOI: 10.1891/1946-6560.3.3.286

Carver, K., Joyner, K., \& Udry, R. J. (2003). National estimates of adolescent romantic relationships. In P. Florsheim (Ed.), Adolescent romantic relations and sexual behavior: Theory, research, and practical implications (pp. 23-56). Mahwah, N.J: Erlbaum.

Centers for Disease Control and Prevention (2014). Understanding teen dating violence. Retrieved online January 7, 2016, from http://www.cdc.gov/violenceprevention/pdf/teendating-violence-factsheet-a.pdf

Cohen, J. (1969). Statistical power analysis for the behavioral sciences. New York: Academic Press.

Cohen. J. (1992). A power primer. Psychological Bulletin, 112, 155-159. DOI: 10.1037/00332909.112.1.155 
Connolly, J., Friedlander, L., Pepler, D., Craig, W., Laporte, L. (2010). The ecology of adolescent dating aggression: Socio-demographic risk factors. Journal of Aggression, Maltreatment \& Trauma, 19, 469-491. DOI: 10.1080/10926771.2010.495028

Cordova, J. V., Jacobson, N. S., Gottman, J. M., Rushe, R., \& Cox, G. (1993). Negative reciprocity and communication in couples with a violent husband. Journal of Abnormal Psychology, 102(4), 559-564. DOI: 10.1037/0021-843X.102.4.559

Creasey, G., \& Hesson-McInnis, M. (2001). Affective responses, cognitive appraisals, and conflict tactics in late adolescent romantic relationships: Associations with attachment orientations. Journal of Counseling Psychology, 48, 85-96. DOI: 10.1037/00220167.48.1.85

Creasey, G., Kershaw, K., \& Boston, A. (1999). Conflict management with friends and romantic partners: The role of attachment and negative mood regulation expectancies. Journal of Youth and Adolescence, 28(5), 523-543. DOI: 10.1023/A:1021650525419

Cui, M.., Ueno, K., Gordon, M., \& Fincham, F. D. (2013). The continuation of intimate partner violence from adolescence to young adulthood. Journal of Marriage and Family, 75(2), 300-313. DOI: 10.1111/jomf.12016

Elliot, D., \& Menard, S. (1996). Delinquent friends and delinquent behavior: Temporal and developmental patterns. In J. D. Hawkins (Ed.), Delinquency and crime: Current theories (pp. 28-67). Cambridge, MA: Cambridge University Press.

Fawson, P. R. (2015). Controlling behaviors as a predictor of partner violence among heterosexual female and male adolescents. Partner Abuse, 6(2), 217-229. DOI: $10.1891 / 1946-6560.6 .2 .217$

Fite, J. E., Bates, J. E., Holtzworth-Munroe, A., Dodge, K. A., Nay, S. Y., \& Pettit, G. S. (2008). 
Social information processing mediates the intergenerational transmission of aggressiveness in romantic relationships. Journal of Family Psychology, 22(3), 367-376. DOI: $10.1037 / 0893-3200.22 .3 .367$

Follingstad, D. R., \& Rogers, M. J. (2013). Validity concerns in the measurement of women's and men's report of intimate partner violence. Sex Roles, 69, 149-167. DOI: 10.1007/s11199-013-0264-5

Follingstad, D. R., Rutledge, L. L., Berg, B. J., Hause, A. S., \& Polek, D. S. (1990). The role of emotional abuse in physically abusive relationships. Journal of Family Violence, 5(2), 107-120.

Foshee, V. A., Benefield, T., Suchindran, C., Ennett, S. T., Bauman, K. E., Karriker-Jaffe, K. J., Reyes, H. M., \& Mathias, J. (2009). The development of four types of adolescent dating abuse and selected demographic correlates. Journal of Research on Adolescence, 19(3), 380-400. DOI: 10.1111/j.1532-7795.2009.00593.x

Fritz, P. A. T., \& O’Leary, K. D. (2004). Physical and psychological partner aggression across a decade: A growth curve analysis. Violence and Victims, 19(1), 3-16. DOI: 10.1891/vivi/19.1.3.33236

Fritz, P. A. T., Slep, A. M. S. (2009). Stability of physical and psychological adolescent dating aggression cross time and partners. Journal of Clinical Child and Adolescent Psychology, 38, 303-314. DOI: 10.1080/15374410902851671

Gomez, A. M. (2011). Testing the cycle of violence hypothesis: Child abuse and adolescent dating violence as predictors of intimate partner violence in young adulthood. Youth \& Society, 43, 171-192. DOI: 10.1177/0044118X09358313

Hamby, S. L., \& Sugarman, D. B. (1999). Acts of psychological aggression against a partner and 
their relation to physical assault and gender. Journal of Marriage and Family, 61, 959970. DOI: $10.2307 / 354016$

Hare, A. L., Miga, E. M., \& Allen, J. P. (2009). Intergenerational transmission of aggression in romantic relationships: The moderating role of attachment security. Journal of Family Psychology, 23, 808-818. DOI: 10.1037/a0016740

Harlow, L. L. (2014). The essence of multivariate thinking: Basic themes and methods: Routledge.

Henderson, A. J. Z., Bartholomew, K., Trinke, S. J., Kwong, M. J. (2005). When loving means hurting: An exploration of attachment and intimate abuse in a community sample. Journal of Family Violence, 20(4), 219-230. DOI: 10.1007/s10896-005-5985-y

Hollingshead, A. B. (1975). Four-factor index of social position. Unpublished manuscript, Yale University.

Holt, M. K., \& Espelage, D. L. (2005). Social support as a moderator between dating violence victimization and depression/anxiety among African American and Caucasian adolescents. School Psychology Review, 34(3), 309-328.

Holtzworth-Munroe, A., Meehan, J. C., Herron, K., Rehman, U., \& Stuart, G. L. (2003). Do subtypes of maritally violent men continue to differ over time? Journal of Consulting and Clinical Psychology, 71(4), 728-740. DOI: 10.1037/0022-006X.71.4.728

Holtzworth-Munroe, A., \& Stuart, G. L. (1994) Typologies of male batterers: Three subtypes and the differences among them. Psychological Bulletin, 116(3), 476-497. DOI: 10.1037/0033-2909.116.3.476

Jelz, D. R., Molidor, C. E., Wright, T. L. (1996). Physical, sexual, and psychological abuse in high school dating relationships: Prevalence rates and self-esteem issues. Child and 
Adolescent Social Work Journal, 13(1), 69-87.

Johnson, M. P. (1995). Patriarchial terrorism and common couple violence Two forms of violence against women. Journal of Marriage and Family, 57(2), 283-294. DOI: $10.2307 / 353683$

Johnson, M. P. (2005). Domestic violence: It's not about gender-or is it? Journal of Marriage and Family, 67, 1126-1130. DOI: 10.1111/j.1741-3737.2005.00204.x

Johnson, M. P. (2006). Conflict and control: Gender symmetry and asymmetry in domestic violence. Violence Against Women, 12(11), 1003-1018. DOI:

$10.1177 / 1077801206293328$

Johnson, M. P., \& Ferraro, K. J. (2000). Research on domestic violence in the 1990s: Making distinctions. Journal of Marriage and Family, 62, 948-963.DOI: 10.1111/j.17413737.2000.00948.x

Jouriles, E. N., Garrido, E., Rosenfield, D., \& McDonald, R. (2009). Experiences of psychological and physical aggression in adolescent romantic relationships: Links to psychological distress. Child Abuse \& Neglect, 33, 451-460. DOI:

10.1016/j.chiabu.2008.11.005

Kline, R. B. (2016). Principles and practice of structural equation modeling (4 ${ }^{\text {th }}$ ed.). New York, NY: The Guilford Press.

Light, R. J., Singer, J. D., \& Willett, J. B. (1990). By design: Planning research on higher education. Cambridge, MA \& London, England: Harvard University Press.

Lloyd, S. A. (1996). Physical aggression and marital distress: The role of everyday marital interaction. In D. D. Cahn \& S. A Lloyd (Eds.), Family violence from a communication perspective (pp. 177-198). Thousand Oaks, CA: Sage. 
Lorber, M. F., \& O’Leary, K. D. (2004). Predictors of the persistence of male aggression in early marriage. Journal of Family Violence, 19(6), 329-338. DOI: 10.1007/s10896-004-0678-5

Margolin, G., John, R. S., Gleberman, L. (1988). Affective responses to conflictual discussions in violent and nonviolent couples. Journal of Consulting and Clinical Psychology, 56(1), 24-33. DOI: $\underline{10.1037 / 0022-006 X .56 .1 .24}$

Moffitt, T. E. (1993). Adolescence-limited and life-course persistent antisocial behavior: A developmental taxonomy. Psychological Review, 100, 674-701.

Moffitt, T. E. (2003). Life-course-persistent and adolescence-limited antisocial behavior: A 10year research review and a research agenda. In B. B. Lahey \& T. E. Moffitt (Eds.), Causes of conduct disorder and juvenile delinquency (pp. 49-75). New York: Guilford.

Moffitt, T. E. (2007). A review of research on the taxonomy of life-course persistent versus adolescence-limited antisocial behavior. In D. J. Flannery, A T. Vazsonyi \& I. D. Waldman (Eds.), The Cambridge handbook of violent behavior and aggression (pp. 4974). New York: Cambridge University Press.

Montgomery, M. J. (2005). Psychosocial intimacy and identity: From early adolescence to emerging adulthood. Journal of Adolescent Research, 20(3), 346-374. DOI: $10.1177 / 0743558404273118$

Murphy, C. M., \& O’Leary, K. D. (1989). Psychological aggression predicts physical aggression in early marriage. Journal of Consulting and Clinical Psychology, 57(5), 579-582. DOI: $\underline{10.1037 / 0022-006 X .57 .5 .579}$

Muthen, L. K., \& Muthen, B. O. (1998-2012). Mplus: Statistical analysis with latent variables. User's Guide. Los Angeles: Muthen \& Muthen.

O’Keefe, M. (1998). Factors mediating the link between witnessing interparental violence and 
dating violence. Journal of Family Violence, 13(1), 39-57. DOI:

10.1023/A:1022860700118

O’Leary, K. D., Malone, J., \& Tyree, A. (1994). Physical aggression in early marriage: Prerelationship and relationship effects. Journal of Consulting and Clinical Psychology, 62(3), 594-602. DOI: 10.1037/0022-006X.62.3.594

O’Leary, K.D., \& Slep, A. M. (2003). A dyadic longitudinal model of adolescent dating aggression. Journal of Clinical Child and Adolescent Psychology, 32(3), 314-327. DOI: 10.1207/S15374424JCC3203_01

Pettit. G. S., Lansford, J. E., Malone, P. S., Dodge, K. A., \& Bates, J. E. (2010). Domain specificity in relationship history, social-information processing, and violent behavior in early adulthood. Journal of Personality and Social Psychology, 98, 190-200. DOI: $\underline{10.1037 / \mathrm{a} 0017991}$

Rogosa, D. (1980). A critique of cross-lagged correlation. Psychological Bulletin, 88(2), 245258. DOI: $10.1037 / 0033-2909.88 .2 .245$

RTI International (2012). New Study of 1,430 7th-Grader Students Reports Teen Dating Violence Behaviors and Risk Factors Occurring among Middle School Students. Retrieved from http://www.rwjf.org/vulnerablepopulations/product.jsp?id=74129

Sabourin, T. C., Infante, D. A., \& Rudd, J. E. (1993). Verbal aggression in marriages: A comparison of violent, distressed but nonviolent, and nondistressed couples. Human Communication Research, 20(2), 245-267. DOI: 10.1111/j.1468-2958.1993.tb00323.x

Sandberg, D. A., Suess, E. A., \& Heaton, J. L. (2010). Attachment anxiety as a mediator of the relationship between interpersonal trauma and posttraumatic symptomatology among college women. Journal of Interpersonal Violence, 25(1), 33-49. DOI:

$10.1177 / 0886260508329126$ 
Schafer, J. L., \& Graham, J. W. (2002). Missing data: Our view of the state of the art. Psychological Methods, 7(2), 147-177. DOI: 10.1037//1082-989X.7.2.147

Silverman, J. G., Raj, A., Mucci, L. A., \& Hathaway, J. E. (2001). Dating violence against adolescent girls and associated substance use, unhealthy weight control, sexual risk behavior, pregnancy, and suicidality. Journal of the American Medical Association, 286(5), 572-579. DOI:10.1001/jama.286.5.572

Simons, R. L., Lin, K., \& Gordon, L. (1998). Socialization in the family of origin and male dating violence: A prospective study. Journal of Marriage and the Family, 60, 467-478. doi: $10.2307 / 353862$

Steinberg, L., Albert, D., Cauffman, E., Banich, M., Graham, S., \& Woolard, J. (2008). Age differences in sensation seeking and impulsivity as indexed by behavior and self-report: Evidence for a dual systems model. Developmental Psychology, 44, 1764-1778. doi:10.1037/a0012955

Stets, J. E. (1990). Verbal and physical aggression in marriage. Journal of Marriage and the Family, 52, 501-514.

Stets, J. E., \& Straus, M. A. (1989). The marriage license as a hitting license: A comparison of assaults in dating, cohabiting, and married couples. Journal of Family Violence, 4, 161180. DOI: $10.1007 / \mathrm{BF} 01006627$

Straus, M. A. (1979). Measuring intrafamily conflict and violence: The conflict tactics (CT) scales. Journal of Marriage and Family, 41(1), 75-88.

Straus, M. A., Hamby, S. L., Boney-McCoy, S., \& Sugarman, D. B. (1996). The revised conflict tactics scales (CTS2): Development and preliminary psychometric data. Journal of Family Issues, 17(3), 283-316. DOI: 10.1177/019251396017003001

Swartout, A. G., Swartout, K. M., \& White, J. (2011). What your data didn't tell you the first 
time around: Advanced analytic approaches to longitudinal analyses. Violence Against Women, 17, 309-321. DOI: 10.1177/1077801211398230

Toewns, M. L., McKenry, P., \& Catlett, B. S. (2003). Male-initiated partner abuse during marital separation prior to divorce. Violence and victims, 18(4), 387-402. DOI:

10.1891/vivi.2003.18.4.387

Tolman, M. (1989). The development of a measure of psychological maltreatment of women by their male partners. Violence and Victims, 4(3), 159-177.

Wheaton, B., Muthén, B., Alwin, D F., \& Summers, G. F. (1977). Assessing reliability and stability in panel models. Sociological Methodology, 8, 84-136.

Williams, T. S., Connolly, J., Pepler, D., Craig, W., \& Laporte, L. (2008). Risk models of dating aggression across different adolescent relationships: A developmental psychopathology approach. Journal of Consulting and Clinical Psychology, 76, 622-632. DOI:

10.1037/0022-006X.76.4.622

Woffordt, S., Mihalic, D. E., \& Menard, S. (1994). Continuities in marital violence. Journal of Family Violence, 9(3), 195-225. DOI: 10.1007/BF01531948

Yarkovsky, N., \& Fritz, P. A. T. (2014). Attachment style, early sexual intercourse, and dating aggression victimization. Journal of Interpersonal Violence, 29(2), 279-298. DOI: $10.1177 / 0886260513505143$ 
Table 1. Correlations and descriptive statistics of composite scores for psychological and physical aggression and control variables $(N=434)$.

\begin{tabular}{|c|c|c|c|c|c|c|c|c|c|c|c|}
\hline Variable & 1 & 2 & 3 & 4 & 5 & 6 & 7 & 8 & 9 & 10 & 11 \\
\hline $\begin{array}{l}\text { 1. Age } 22 \\
\text { Psych }\end{array}$ & - & & & & & & & & & & \\
\hline $\begin{array}{l}\text { 2. Age } 22 \\
\text { Phy }\end{array}$ & $.60^{* * * *}$ & - & & & & & & & & & \\
\hline $\begin{array}{l}\text { 3. Age } 23 \\
\text { Psych }\end{array}$ & $.60^{* * * *}$ & $.33^{* * * *}$ & - & & & & & & & & \\
\hline $\begin{array}{l}\text { 4. Age } 23 \\
\text { Phy }\end{array}$ & $.26^{* * *}$ & $.25^{* * * *}$ & $.48^{* * *}$ & - & & & & & & & \\
\hline $\begin{array}{l}\text { 5. Age } 24 \\
\text { Psych }\end{array}$ & $.49^{* * * *}$ & $.27^{* * * *}$ & $.64^{* * * *}$ & $.28^{* * * *}$ & - & & & & & & \\
\hline $\begin{array}{l}\text { 6. Age } 24 \\
\text { Phy }\end{array}$ & $.24^{* * *}$ & $.34^{* * * *}$ & $.32^{* * * *}$ & $.38^{* * * *}$ & $.56^{* * *}$ & - & & & & & \\
\hline $\begin{array}{l}\text { 7. Age } 25 \\
\text { Psych }\end{array}$ & $.55^{* * *}$ & $.29^{* * * *}$ & $.53^{* * * *}$ & $.23^{* * *}$ & $.71^{* * * *}$ & $.30^{* * * *}$ & - & & & & \\
\hline $\begin{array}{l}\text { 8. Age } 25 \\
\text { Phy }\end{array}$ & $.30^{* * *}$ & $.37^{* * * *}$ & $.33^{* * * *}$ & $.30^{* * * *}$ & $.44^{* * *}$ & $.40^{* * *}$ & $.48^{* * * *}$ & - & & & \\
\hline 9. Sex & .07 & .05 & & & & & & & & & \\
\hline 10. Race & -.06 & .10 & & & & & & & & & \\
\hline 11. SES & -.01 & -.02 & & & & & & & & & \\
\hline$M$ & .54 & .06 & .51 & .07 & .53 & .07 & .56 & .05 & .54 & .16 & 3.37 \\
\hline$S D$ & .52 & .14 & .51 & .23 & .52 & .19 & .51 & .13 & .50 & .37 & 1.15 \\
\hline
\end{tabular}

Note. Psych (Psychological Aggression). Phy (Physical Aggression). Control variables are correlated only with age $22 .{ }^{* * *} p<.001$. 
Psychological Aggression

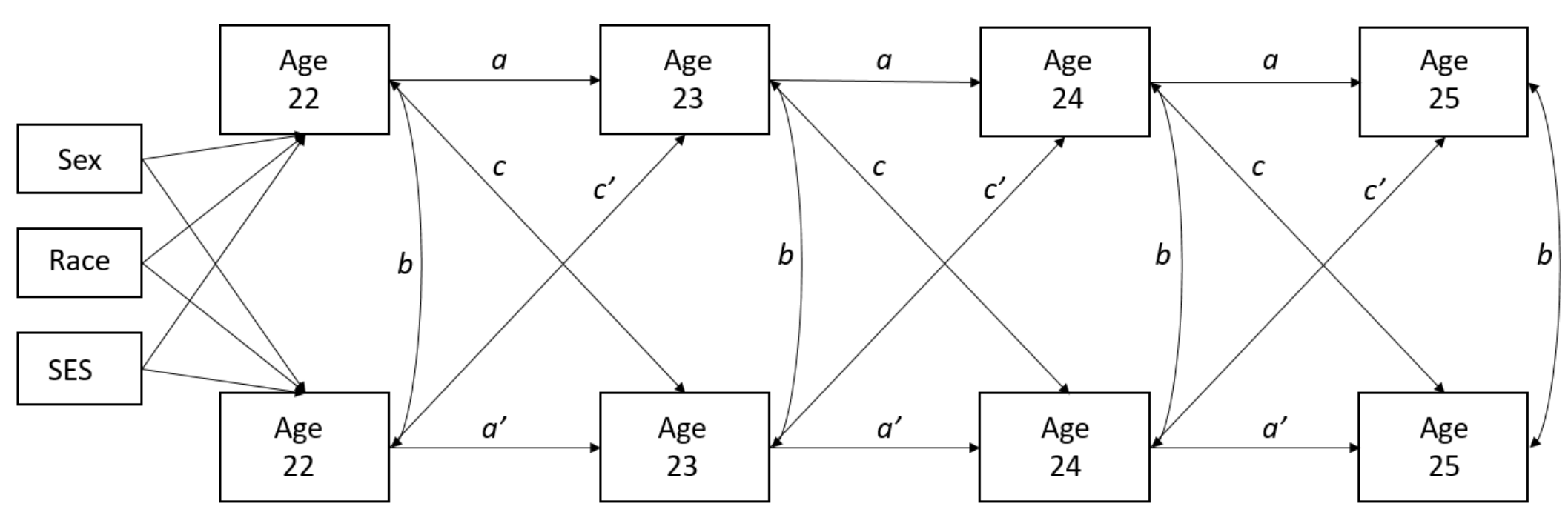

Physical Aggression

Figure 1. Hypothesized cross-lag model across four waves $(N=434)$. 


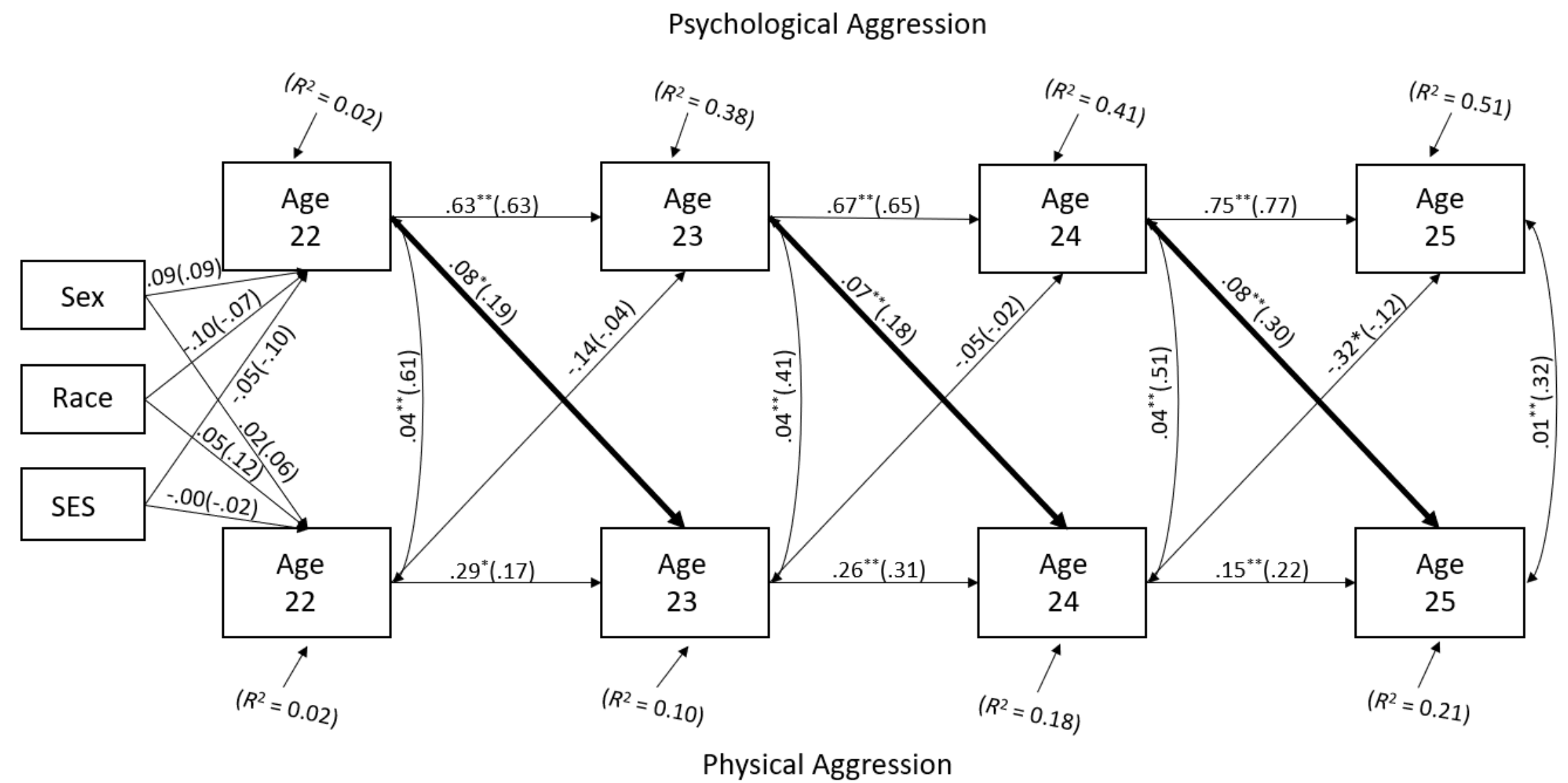

Figure 2. Cross-lag model of early psychological aggression predicting later physical aggression, and early physical aggression predicting later psychological aggression. Standardized coefficients are in parentheses $(N=434) .{ }^{*} p<.05,{ }^{*} p<.01$ 